Буйчик А.Г. Психологическая культурология как новая наука / Е.А. Аброзе, А.Г. Буйчик, С.В. Лебедев // «Вопросы современной науки»: коллект. науч. монография; [под ред. Н.Р. Красовской]. - М.: Изд. Интернаука, 2016. - С. 22-40. Т. 11.

ISBN 978-5-9908551-0-6

Буйчик Александр Геннадьевич,

$\mathrm{PhD}$ социальных наук,

ЧОУ ВО «Санкт-Петербургский институт искусств и реставрации»

Тел.: +79217702472

e-mail: info@ buychik.ru

\title{
ВОПРОСЫ СОВРЕМЕННОЙ НАУКИ
}

Том 11, 2016 год

ГЛАВА 2.

ПСИХОЛОГИЧЕСКАЯ КУЛЬТУРОЛОГИЯ КАК НОВАЯ НАУКА

PhD Social Sc., Alexander G. Buychik, St. Petersburg Institute of Arts and Restoration, Russia Тел.: +79217702472 e-mail: info@buychik.ru

\section{QUESTIONS OF MODERN SCIENCE}

Vol. 11, 2016.

CHAPTER TWO.

PSYCHOLOGICAL CULTURAL STUDIES AS A NEW SCIENCE 


\section{Введение}

На современном этапе развития общества научный мир постоянно сталкивается с проблемой определения тех или иных явлений, которые тяжело отнести к одной из наук, тем более, к одному из научных течений или школе. Данная проблематика начала возникать ещё во времена Древней Греции, когда философия бурно развивалась и расширяла свою базу данных.

Если мы будем рассматривать формирования новых наук, то заметим, что на первичном этапе новое направление формируется в пределах определённой науки и ещё длительное время остаётся внутри, определяясь в направлении и формируя собственную школу. В дальнейшем научный мир осознаёт необходимость проведения ревизии, или аудита, сформированных и развивающихся направлений с целью подтверждения актуальности выделения какого-либо направления науки в отдельную науку.

Данный путь, как мы можем видеть, прошли практически все современный науки, который ныне агломерируются в комплексы наук, а те в свою очередь - в группы наук. Физика, химия, биология, история, культурология, искусствоведение, психология, социология и многие другие комплексы наук имеют уже многовековую историю своего формирования и развития вне первонауки - философии [7].

В последние 25-30 лет по нарастающей увеличилась активность учёных в обсуждении сепарирования новых научных течений и наук, которые основываются на принципе трансграничности, т.е. возникла реальная потребность в осмыслении научного опыта, приобретённого в различных, в основном, смежных науках, который формирует потребность в новых предметах и методах исследования, уже не вмещающихся в пространство бытующих наук. Следовательно, система наук претерпевает локальные изменения внутри групп. Если ярким «классическим» примером сформированной в своё время трансграничной науки может являться «астрономия», то на современном этапе наукоразвития это, например, «семиотика», которая активно пользуется 
научным опытом и методами исследования наук комплексов филологии, культурологии, математики, физики и ряда других.

В данной монографии кратко представлен исследовательский опыт, который привёл к актуализации формирования новой науки «психологическая культурология», имеющей все признаки трансграничности, ведущей к сепарированию данного направления как от культурологии, так и психологии, а также и социологии, т. к. использует предметы, методы и инструменты исследования всех перечисленных выше комплексов наук и ряда других.

\section{1 Актуальность. Психологическая культурология в системе социально-гуманитарной группы наук}

Культура, как производная психической деятельности человека, в современном мире становится многогранным, разноаспектным феноменом, базирующимся на присущей ей разветвлённой внутренней структуре и поддерживающим огромное количество функций в обществе, в том числе психологически обусловленных. Множество элементов культуры отличаются особой подвижностью во времени, оперативностью реагирования и точностью передачи особенностей периода, корреляциями с психическими процессами социума, что составляет особый интерес для исследований не только в ракурсе культурологии, но и психологии. Изыскания учёных в широком спектре ряда гуманитарных наук, таких как психология, культурология, социология, антропология, представляют собой мощный пласт теоретической и практической базы для широкомасштабной научной работы.

Комплексное изучение психолого-культурологических процессов, описание их функций в рамках культурологии и широкого спектра психологического знания, позволяет говорить о появлении новой науки психологической культурологии.

Раскрытие психологических, культурологических, социальных, культурно-антропологических особенностей механизмов этих процессов не только модернизирует научное поле, но и выступает как инновация в научном 
знании, выводит на первый план острую необходимость применения нового методологического подхода к проблемам комплексного междисциплинарного изучения явлений актуальных как для психологии, так и для культурологии.

Предмет психологической культурологии - исследование воздействия общества и различных социальных групп на сферу культуры в темпоральном и содержательном развитии, и наоборот, влияние культуры на формирование психологического состояния социумов и отдельных социальных групп.

Следовательно, в психологической культурологии предметом исследования является как общество в целом и индивид в отдельности, так и культура как феномен развития общества. Данная объектная дихотомия определяет одну из особенностей науки «психологическая культурология».

Методологическая составляющая психологии и культурологии даёт возможность не только проследить эволюцию психолого-культурологических процессов - первичного объекта изучения новой науки, и способствовать более глубокому проникновению в суть изменений, происходящих в психологокультурологическом и социокультурном пространстве мира на настоящем этапе. Кроме того, методы психологии и культурологии позволяют провести анализ историко-культурных процессов - вторичного объекта психологической культурологии, в динамике их развития.

В рамках психологической культурологии применяются основные методы теоретической и практической психологии. В России в течение уже длительного времени пользуется признание и сохраняет свою актуальность в наши дни многоуровневая и многоаспектная классификация советского психолога, профессора МГУ Бориса Григорьевича Ананьева. Касательно психологической культурологии мы также можем её использовать.

1. Организационные методы, непосредственно связанные со стратегией психологического исследования; с помощью этих методов строится весь цикл исследования и регулирования взаимодействия всех других методов. 
2. Эмпирические способы добывания научных данных, получения фактов. Это самая обширная группа методов, из которой в психологической культурологии более актуальны и могут быть чаще применимы:

- $\quad$ обсервационные методы (наблюдение и самонаблюдение);

- экспериментальные методы, а именно полевой и естественный;

- психодиагностические методы, а именно стандартизованные и проективные тесты, анкеты и опросники, социометрия, интервью и беседа;

- $\quad$ праксиметрические методы - приёмы анализа процессов и продуктов деятельности;

- $\quad$ моделирование - математическое и кибернетическое.

3. Приёмы обработки данных:

- количественный (математико-статистический) анализ;

- $\quad$ качественный анализ, дифференцирующий материал по типам, группам, вариантам, т.е. составление психологической казуистики, то есть описание случаев как наиболее полно выражающих типы и варианты, так и являющихся исключениями или нарушениями центральных тенденций.

4. Интерпретационные методы, составляющие различные варианты генетического и структурного методов. По Б.Г. Ананьеву, различные варианты генетического метода есть способы теоретического исследования генетических (онтогенетических, патогенетических) связей между изучаемыми явлениями. Взаимосвязи между частями и целым, то есть функцией и личностью, определяются структурными методами (психографией, типологической классификацией, психологическим профилем) [4; 5].

Однако для раскрытия всех механизмов динамики развития психологических составляющих социумов в общем и социальных групп в частности в психологической культурологии также, как альтернатива, могут использоваться методы, более распространённые в своём квалификационном грейдировании на Западе [8; 12] Ниже кратко рассмотрим их.

1. Наблюдение - целенаправленное восприятие и регистрация поведения исследуемого объекта. Причём все явления при использовании этого метода 
изучаются в обычных для объекта условиях. Этот метод считается одним из самых древних. Но именно научное наблюдение получило широкое применение только в конце XIX в. В психологической культурологии акцентированное внимание уделяется тем видам метода наблюдения теоретической психологии, которые базируются на непосредственной практической составляющей:

- $\quad$ полевое;

- $\quad$ непосредственное;

- включённое;

- $\quad$ прямое;

- сплошное;

- выборочное;

- $\quad$ систематическое;

- несистематическое.

2. Эксперимент - опыт, проводимый в определённых условиях для того, чтобы получить новые данные через непосредственное вмешательство экспериментатора в жизнедеятельность испытуемого. В процессе исследования учёный изменяет определённый фактор/факторы и смотрит, что происходит в результате. В психологической культурологии наибольшее значение также имеют те виды экспериментов, которые максимально приближены к практической составляющей:

- $\quad$ естественный - проводится в обычных условиях и человек может даже не знать об эксперименте;

- проектный - проводится в условиях моделирования определённых условий на основании имеющейся базы данных по аналогичным ситуациям и реакциям человека на эти ситуации;

• пилотажный - пробный эксперимент, проводимый перед основным.

По уровню осознанности эксперименты в культурной психологии сохраняют своё значение:

- $\quad$ явный - испытуемый в курсе эксперимента и всех его подробностей; 
- $\quad$ скрытый - испытуемый не знает всех подробностей эксперимента или вообще не ведает об эксперименте;

- комбинированный - испытуемый знает только часть информации или намеренно введён в заблуждение относительно эксперимента.

3. Психологическое тестирование - это изучение психологических качеств и свойств личности через применение психологических тестов. В культурологической психологии используются те виды психологического тестирования, которые ориентированы на определение состояния социальных групп:

- тесты личности - для изучения характера, потребностей, эмоций, способностей и других свойств личности;

• $\quad$ тесты интеллекта - для изучения степени развития интеллекта;

- вербальные тесты - для изучения умения человека описывать словами совершаемые действия.

4. Опрос - вербально-коммуникативный метод, в процессе которого происходит взаимодействие между исследователем и изучаемым человеком. Это массовый метод, потому что применяется для получения сведений о группе людей, а не об одном человеке. Опросы разделяют на:

- стандартизированные - строгие и дающие общее представление о проблеме;

- $\quad$ нестандартизированные - менее строгие и позволяют изучать нюансы проблемы.

В психологической культурологии используются активные виды опросов:

- $\quad$ устный - позволяет проникнуть в психологии человека более глубже, чем письменный;

- $\quad$ виртуальное анкетирование - предварительные ответы на вопросы перед основной беседой;

• $\quad$ личностные тесты - для определения психических особенностей личности в рамках определённой социальной группы;

- $\quad$ интервью - личная беседа. 
Также психологическая культурология использует основные культурологические методы социогуманитарного познания. Общие методы [6; 15]:

- диалектический - рассмотрение культуры как развивающегося, внутренне противоречивого, многостороннего явления, требующего конкретного изучения;

- $\quad$ системный - рассмотрение культуры как системы, элементы которой тесно взаимодействуют и находятся в единстве;

- структурно-функциональный - выделение и рассмотрение элементов, составляющих культуру, в том числе, выявление роли каждого элемента в её функционировании;

- $\quad$ компаративный - историческое изучение и сравнение культур в процессе их взаимодействия по какому-либо основанию, признаку, установление закономерностей развития нескольких культур;

- типологический - сравнение культур с целью обобщения их характеристик, т.е. изучение структуры культуры путём восхождения от абстрактного к конкретному и выявления на этой основе типологической близости и историко-культурного процесса.

Из частных культурологических методов психологическая культурология использует следующие методы [6; 15]:

- культурантропологический - рассмотрение механизмов передачи культурных навыков от человека к человеку;

- семиотический - изучение знаковой системы культурного объекта;

- герменевтический - толкование сложных и многозначных текстов, нацеленное на получение знаний и понимание феномена культуры;

- $\quad$ исторический - анализ предпосылок, процесса возникновения, этапов развития изучаемого культурного явления;

- $\quad$ синхронистический - анализ культурных объектов в одном выбранном промежутке времени без обращения к исторической перспективе, но с разных сторон; 
- археологический - исследование и анализ материальных предметов, добытых в результате раскопок;

- $\quad$ психологический - исследование субъективных механизмов деятельности культуры, индивидуальных качеств и бессознательных психических процессов.

В процессе психолого-культурологического анализа также используются методы полевой этнографии:

- $\quad$ описание,

- классификация,

- наблюдение,

- $\quad$ открытые интервью.

Предпринятый анализ научных работ, созданных сфере междисциплинарных исследований психологии и культурологии, демонстрирует обратимость исследования психолого-культурологических процессов. Необходимо отметить, что феномен обратимости процессов неоднократно подтверждался точными и естественными науками, например, математикой, физикой и химией.

Психологическая культурология является трансграничной наукой социально-гуманитарного характера. Трансграничность базируется на следующих фундаментальных принципах использования достижений науки:

- область исследования;

- методы исследования;

- результаты исследования.

Трансграничность можно дифференцировать по принципу определения объёма использования достижений смежных наук. Поэтому непосредственная трансграничность психологической культурологии определяется тремя комплексами наук социально-гуманитарной группы:

1) культурологией - комплексом наук, изучающих культуру, её историю, сущность, закономерности функционирования и развития; 
2) психологией - комплексом наук, изучающих закономерности возникновения, развития и функционирования психики и психической деятельности человека и групп людей;

3) социологией - комплексом наук об обществе, системах, составляющих его, закономерностях его функционирования и развития, социальных институтах, отношениях и общностях.

Опосредованную трансграничность с психологической культурологией мы находим в следующих научных комплексах:

1) философия - комплекс наук о наиболее общих законах существования природы, человека, общества и сознания, о мире и отношении человека к миру;

2) история - комплекс наук, изучающих источники о прошлом для того, чтобы установить последовательность событий, исторический процесс, объективность описанных фактов и сделать выводы о причинах событий;

3) антропология - комплекс наук, занимающихся изучением человека, его происхождением, развитием, существованием в естественной и культурной средах.

Таким образом, на современном этапе развития общества становится актуальным выделение трансграничной науки «психологическая культурология», которая в силу разнородности и многообразия трансграничности не может быть причислена ни к одному из комплекса наук, но чётко определяет своё место в системе социально-гуманитарных наук.

\section{2 Социально-философское обоснование психологической} культурологии

XX в. с его мировыми войнами, массовым геноцидом, экологическими проблемами привёл к разочарованию в прогрессе и самой вере в то, что человек вообще способен изменить этот мир к лучшему. «Возможна ли поэзия после Освенцима»? - задавали вопрос многие деятели культуры после катаклизмов ХХ в. Экологический кризис обесценил великую идею преобразования и покорения 
природы. Почти достигнутая победа человека над природой оказалась на самом деле мнимой, равносильной поражению. Этот кризис парализовал, убил прежний оптимизм, устремленность в светлое будущее, ибо последнее оказалось слишком пугающим. В равной мере он обесценил открывшиеся возможности общества потребления. Он как бы отравил положительные и привлекательные стороны такого общества, создал ситуацию, похожую на пир во время чумы. Экологический кризис все сделал хрупким, временным, эфемерным и обречённым.

Даже человек как личность в новые времена оказался уже не венцом творения. Если в Средневековье считалось, что человек создан по образцу и подобию Божию, если после Декарта человек считался животным, но наделенный разумом, в отличие от всех других живых существ, то после Фрейда человек стал таким же животным, живущим своими инстинктами. Даже деление на мужчин и женщин после «сексуальной революции» и подъема феминизма сделалось не обязательным. В начале XXI в. те, кто ранее считался извращенцами, вдруг сделались представителями «меньшинств», которые начали требовать себе «прав».

И, как результат, старая эпоха с её ценностями кончается, а новая ещё не наступила. Словом, наступил «постмодерн». Действительно, можно сказать, что прежние «классические» научные системы, рождённые в XIX в., в эпоху модерна, уже не могут претендовать на объяснение всех особенностей развития природы. XIX в. было веком создания универсальных научных систем. Ньютоновская физика, таблица Менделеева, теория Ч. Дарвина, наконец, философия и экономическая теория К. Маркса - все они вместе предлагали логичную и убедительную картину природы и общества. Но вот уже более столетия эта картина не может считаться научной. Современная физика не может дать определение материи или поля. Аналогичным образом, медицина не дает определения жизни. Дарвинизм немного способен дать для объяснения клонирования. 
Но всё это не означает появления более или менее устоявшихся четких альтернативных классике теорий. В этом смысле, сейчас в науке действительно наступила эпоха «постклассики». И философия в итоге также оказывается в состоянии «постмодерна».

Итак, в наше время философский «постмодерн» есть всего лишь констатация того факта, что человечество зашло в тупик, но при этом не знает ни того общества, в котором живет, ни того, как найти выход из тупика, что продолжается уже около 50 лет. В самом общем виде постмодерн выражает глубокое разочарование в итогах всего предшествующего развития, утрату веры в человека и гуманизм, разум и прогресс, во все прежние идеалы и ценности. Со смешанными чувствами тревоги, сожаления, растерянности и боли человечество приходит к пониманию того, что ему придётся отказаться от мечты о светлом будущем. Не только светлое, но будущее вообще становится всё более проблематичным. Все прежние цели и задачи сводятся теперь к одному - к проблеме выживания и чисто биологическому потреблению. Человек постмодерна как бы утратил почву под ногами, оказался в невесомости или сомнамбулическом состоянии, из которого никак не может выйти.

Понятно, что человек эпохи «пост», оглушенный информационным взрывом, господством СМИ и клиповым мышлением, превратился в жертву собственных страхов и неврозов. И всё это более чем, нашло отражение в т.н. «современном искусстве».

Начало XXI в. войдёт в историю как время безвременья. Никаких великих идей, никаких великих подвигов, даже никаких великих преступлений.

Ещё недавно в мире господствовали великие идеологии, предлагавшие свои альтернативы существующему порядку вещей. Сейчас же каких-либо внятных идейных альтернатив не видно. Различные экологические, феминистские и антиглобалистские организации и не претендуют на создание глобальных позитивных теорий. И это не те идеи, за которые можно отдать жизнь. 
То, что происходит в мире, печально. Западная цивилизация, при всех ее бесчисленных минусах, всё же обеспечила феноменальный подъём человечества. Теперь же африканские и восточные традиции, которые будут доминировать в мире нового века, вряд ли способны обеспечить его дальнейшее развитие. Похоже, что падение западной цивилизации будет напоминать аналогичное падение античного мира, которое сменили «тёмные века».

Россия же в постзападном мире может занять ведущее место, если только не забудет, что является евразийской страной, имеющей свой путь развития. Но для этого Россия должна по-новому оценить своё культурное достояние и развивать свою культуру с упором на свои исконные традиции. И самым важным в этом будет именно психологическая готовность действовать и творить, а не только различные экономические и политические мотивы.

Но что скажет на это наука о культуре?

Культурология, которая есть совокупность исследований культуры как структурной целостности, всегда опиралась на психологию человека. Все без исключения направления культурологии в той или степени базируются на эмоциональных чувствах. Разумеется, есть и собственно психологическое направление в культурологии. Оно ориентирует исследователя на изучение субъективных механизмов деятельности культуры, индивидуальных качеств, бессознательные психические процессы. Этот метод очень важен при исследованиях особенностей всех национальных культур.

Это направление сформировалось во второй половине XIX в. И к настоящему времени прошло ряд этапов.

В XX в. в качестве теоретиков выдвинулась целая группа философов, представлявших «Франкфуртскую школу» (среди них особенно популярен был Г. Маркузе), ряд социологов (среди них выделялся Ч.Р. Миллс, автор самого термина «новые левые»), а также на редкость разношёрстная группа деятелей «контр-культуры», противопоставивших себя прежней официозной культуре. Чтобы понять, в чём сущность философии «новых левых», рассмотрим 
воззрения Герберта Маркузе, самого известного из теоретиков этого направления.

В «Одномерном человеке», основной своей книге, написанной в 1964 г., Маркузе говорит о том, что технический прогресс создаёт такие формы жизни, которые примиряют оппозиционные силы. Более того, видимо, наибольшим достижением индустриального общества стала его способность воспрепятствовать изменениям, порождать партнерские отношения между трудом и бизнесом. И буржуазия, и пролетариат движутся в одном направлении, преследуют общие цели и разделяют фактически одни и те же политические идеалы. Интегрированность пролетариата как бы приобретает тотальный характер и охватывает все сферы общества.

Рабочий и предприниматель смотрят одни и те же фильмы, телепередачи, читают одни и те же газеты, слушают одно и то же радио. Поэтому не приходится удивляться сколь, многое их объединяет. В современном мире, по-прежнему, считает Маркузе, существуют два основных класса: рабочий и буржуа, однако, в этом мире «произошли такие структурные и функциональные изменения этих двух классов, что они, по-видимому, больше не являются носителями исторических преобразований. Скрытая заинтересованность в сохранении и совершенствовании существующих институтов примиряет эти ранее антагонистические классы во все увеличивающемся масштабе» [2, с. 12-13]. В результате Запад превратился в общество без оппозиции.

Маркузе, таким образом, отмечал факт приобщения к почти одинаковой массовой культуре представителей самых разных, в том числе противоположных социальных классов, что приводило к утрате всякого стремления изменять мир и полному «интегрированию в систему».

Выход из положения теоретики неомарксизма предлагали выйти с помощью создания контр-культуры. И действительно, в 1960-80-х гг. контркультура получила широчайшее развитие во многих странах Запада. Рок-музыка, альтернативное кино, бесчисленные поп-, оп- и прочие «арты» стали самой яркой чертой тех лет. Главной чертой контр-культуры было разочарование в массовом 
западном обществе, поиск новых духовных и нравственных ориентиров, ради которых стоит жить. Разумеется, контр-культура, став популярной и модной, очень быстро слилась с официальной культурой, которой должна была противостоять. Исполнители песен протеста и кинорежиссеры, мечтавшие с помощью электрогитар и кинокамер «взорвать систему», стали официально признанными классиками, получавшими баснословные гонорары. Участники студенческих беспорядков 1968 г., повзрослев, сменили джинсы на строгие костюмы и стали председательствовать в банках и крупных транснациональных корпорациях.

Одновременно жесточайшее идеологическое противостояние двух мировых социальных систем закончилось поражением социалистического лагеря, причем это поражение объяснялось не победой западной идеологии, а лишь предательством властвовавших элит стран «реального социализма».

Важную роль в формировании психологической концепции сыграла теория 3. Фрейда и его последователей. Вообще философскую мысль ХХ в. нельзя представить без имени Зигмунда Фрейда. Он не был философом в буквальном понимании, то есть Фрейд как психиатр по профессии писал на темы бессознательного, теории личности, техники лечения неврозов и пр. Его главным вкладом в науку считается психоанализ - психологическая теория, на основании которой возникло особое направление в лечении психических расстройств. Однако созданный им психоанализ оказал огромное влияние на литературу и искусство, педагогику, психологию, социологию, литературоведение, этнографию и ряд других гуманитарных дисциплин. Литература «потока сознания», сюрреализм, «психоделическая» музыка, особенности кинематографического языка - всё это испытало непосредственное влияние фрейдизма.

Ученик Фрейда Карл Густав Юнг ввёл также понятие «коллективного бессознательного». По мысли Юнга, помимо непосредственного сознания индивида существует вторая психическая система - коллективной, универсальной и безличной природы, тождественная у всех индивидов. 
Коллективное бессознательное не развивается индивидуально, но наследуется. Оно состоит из архетипов - универсальных, изначальных, врожденных психических структур, составляющих содержание коллективного бессознательного, распознаваемых в нашем опыте и обнаруживаемых, как правило, в образах и мотивах сновидений.

Впрочем, в вопросах искусства фрейдизм свел всю художественную деятельность к различного рода галлюцинациям, бреду и, в конечном счёте, к либидо. В результате фрейдизм в «сексуальной революции» конца ХХ в. стал тем же, чем был марксизм в социальных революциях того же столетия. В будущем Фрейд будет считаться одним из тех, кто способствовал вырождению и гибели западной цивилизации.

В настоящее время широкое распространение получила этнопсихологическая школа, к виднейшим представителям которой принадлежит американскому этнографу Маргарет Мид (1901-1978 гг.), которая исследовала отношения между различными возрастными группами в традиционных и современных обществах. С именем Мид связан ряд новых научных идей - о природе родительских чувств, соотношении материнских и отцовских ролей, происхождении мужских и женских инициации. Со временем многие понятия М. Мид стали применять не только в этнографических исследованиях.

Разумеется, этими именами психологическая культурология не исчерпывается. Имена, концепции и практика деятелей этого направления заслуживают дальнейшего рассмотрения.

Таким образом, психологическая культурология как отдельная наука имеет социально-философское обоснование, которое также подтверждает её явную трансграничность и, в то же время, логическую последовательность от культурологии, психологии и социологии в плоскости своего генезиса.

\section{3 Разделы и направления психологической культурологии}


На современном этапе развития трансграничной науки «психологическая культурология» уже наглядно сформировались направления, которые можно сгруппировать в научные направления на основании многолетних исследований психологов и культурологов. Основная проблема анализа многочисленных социальных процессов во второй половине XX в. и в начале XXI в. заключалась в незримом отсутствии комплексной единой оценки, которая бы не раздваивалась на несколько отдельных научных исследований, которые в дальнейшем приходилось соединять в единое целое, если вообще соединялось, а проектировалась гармоничным комплексом как единое исследование социальнопсихологического, социально-культурного и психолого-культурологического характера.

В психологической культурологии выделаются пять основных разделов по направлениям социальной активности человека.

1. Индивидуумы объединяются в народы, которые формируют единую систему материальных и нематериальных культурных ценностей. Культурные ценности формируют окружающую среду человека в рамках этноса или народа. Абитология (лат. habitat - окружающая среда) - раздел психологической культурологии, изучающий влияние психологического состояния социальной среды народа или народов определённой территории на тенденции изменения материального и нематериального культурного наследия.

В рамках данного раздела мы выделяем два направления, разграничивая их по сути материальной и нематериальной составляющей, формирующейся во времени:

1) Психология формирования материальной культуры социума направление абитологии, раздела психологической культурологии, которое изучает особенности и тенденции развития общества или народности, влияющие на темпоральное формирование его материальной культуры (архитектуры, живописи, объектов декоративно- прикладного искусства); 
2) Психология формирования нематериальной культуры социума направление абитологии, раздела психологической культурологии, которое изучает особенности и тенденции развития общества или народности, влияющие на темпоральное формирование его нематериальной культуры (устные традиции, фольклор, исполнительские искусства).

2. Человек современный может быть назван уже человеком информационным или человеком урбанистическим по характеру своей концентрации или возрастающей тенденции к концентрации. Урбанизация формирует свои социальные сообщества, которые в свою очередь уже вторично влияют на первичную культурную оболочку или же формируют новую уникальную культурную оболочку полно- урбанистического или сегментарноурбанистического характера. Урбанология (лат. urbanus - городской) - раздел психологической культурологии, изучающий влияние городской среды, её материального и нематериального культурного наследия на психику различных социальных групп и их культурное развитие в рамках социума.

Так как в данном разделе мы видим два типа генезиса урбанистической культуры, то рассматриваются четыре направления - по два относительно материального и нематериального культурного наследия:

1) Психология материального урбанистического культурного наследия направление урбанологии, раздела психологической культурологии, которое изучает историю и тенденции влияния материального культурного наследия (архитектуры, живописи, объектов декоративноприкладного искусства) на формирование психологического состояния определённых социальных групп и их культурное развитие в рамках изучаемого общества или общественной формации;

2) Психология нематериального урбанистического культурного наследия направление урбанологии, раздела психологической культурологии, которое изучает историю и тенденции влияния нематериального культурного наследия (устные традиции, фольклор, исполнительские 
искусства) на формирование психологического состояния определённых социальных групп и их культурное развитие в рамках изучаемого общества или общественной формации;

3) Психология формирования урбанистической материальной культуры направление урбанологии, раздела психологической культурологии, которое изучает формы современного влияния материального культурного наследия (архитектуры, живописи, объектов декоративно-прикладного искусства) на формирование психологического состояния определённых социальных групп и их культурное развитие в рамках действующего общества;

4) Психология формирования урбанистической нематериальной культуры направление урбанологии, раздела психологической культурологии, которое изучает формы современного влияния нематериального культурного наследия (устные традиции, фольклор, исполнительские искусства) на формирование психологического состояния определённых социальных групп и их культурное развитие в рамках изучаемого общества или общественной формации.

Именно этот раздел психологической культурологии имеет наиболее перспективный характер своего развития в силу не только урбанистических процессов мирового сообщества, но и интенсивного развития внутриурбанистических явлений, комплексно относящихся и к социологии, и психологии, и культурологии.

3. Очень важной частью развития и формирования любого общества и человека в отдельности является мода. Нельзя думать, что она пришла в наш дом только с телевидением и бутиками. Мода незримо существует среди нас всю эпоху становления человека разумного. Моду также можно представить, как материальную и духовную, что по объяснимой причине пока не рассматривается с точки зрения науки. Однако психологическая культурология как раз имеет возможность изучать моду и в данной плоскости. Фешинология (англ. fashion мода) - раздел психологической культурологии, изучающий влияние культуры, 
материального и нематериального культурного наследия, на индустрию моды и психологическое развитие различных социальных групп, и наоборот, влияние отдельных представителей различных социальных групп на психологическое развитие общества через трансформацию материального и нематериального культурного наследия в области моды.

Как и в урбанологии, в фешинологии развита обратимость первичного и вторичного, поэтому систематизация направлений может исходит из данного процесса. Однако мы предлагаем систематизировать направления фешинологии согласно академическим параметрам - социологии, психологии и культурологии:

1) Психология моды - направление фешинологии, раздела психологической культурологии, которое изучает влияние культурологического состояния общества на индустрию моды, а также, влияние отдельных представителей различных социальных групп на психологическое развитие общества через трансформацию материального и нематериального культурного наследия в области моды;

2) Социально-психологическое развитие культуры моды - направление фешинологии, раздела психологической культурологии, которое изучает влияние культуры, материального и нематериального культурного наследия;

3) Культурные модальности моды - направление фешинологии, раздела психологической культурологии, которое изучает влияние отдельных сегментов моды на формирование культуры определённого этноса, народа, социума или его социальной группы через психологическое состояние и его изменения.

4. Общество активно формирует виртуальное пространство, которое становится частью культурного облика. В тоже время сама культура абсорбируется в интернет-пространстве и занимает там определённое место и сегменты в стремлении позиционирования и лоббирования информации о культурном наследии и современных культурных ценностях различного рода. 
Металогия (от греч. $\mu \varepsilon \tau \alpha$ - вместе с чем-либо, после чего-либо) - раздел психологической культурологии, изучающий влияние антропогенной составной виртуального пространства на формирование культурных ценностей, а также материального и нематериального культурного наследия.

Направления:

1) Социальная металогия - направление металогии, раздела психологической культурологии, которое изучает влияние антропогенной составной виртуального пространства на формирование культурных ценностей, т.е. тенденции и формы переноса антропогенной активности в социальных сетях на новые течения в культуре общества;

2) Эредитатная металогия (от лат. hereditatem - наследие) - направление металогии, раздела психологической культурологии, которое изучает влияние антропогенной составной виртуального пространства на формирование материального и нематериального культурного наследия, т.е. тенденции и формы антропогенной активности в социальных сетях, которые являются маркерами формирования будущего культурного наследия общества.

5. Ещё одним важным аспектом формирования и трансформации общества как единого комплекса многочисленных процессов является сама динамика, которая подробно изучается в естественных и социальных науках. Однако исследование динамики развития культуры в контексте развития психологических характеристик общества находится ещё на зачаточном уровне по причине сложности формирования целостной картины проектов исследования динамических структур в области культуры. Культурологическая

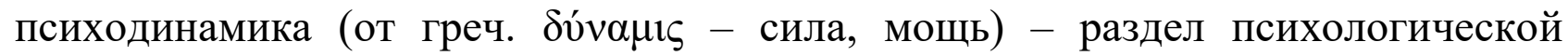
культурологии, изучающий особенности процесса изменения культурологического состояния общества, связанного с психологическими трансформациями в развитии различных социальных групп. Связана изначально с психодинамикой - разделом психологии, изучающим взаимодействие разных 
частей сознания человека, их способность порождать эмоциональные и мотивационные силы, определяющие состояние разума и поведение человека.

Направления:

1) Психодинамика материальной культуры - направление культурологической психодинамики, раздела психологической культурологии, которое изучает особенности процесса изменения материальной культуры (архитектуры, живописи, объектов декоративно-прикладного искусства) общества вследствие психологической трансформации в развитии определённого этноса, народа, социума или отдельной социальной группы.

2) Психодинамика нематериальной культуры - направление культурологической психодинамики, раздела психологической культурологии, которое изучает особенности процесса изменения нематериальной культуры общества (устные традиции, фольклор, исполнительские искусства) вследствие психологической трансформации в развитии определённого этноса, народа, социума или отдельной социальной группы.

Таким образом, психологическая культурология исследует все основные процессы развития общества, социальных групп внутри общества и отдельных индивидуумов в контексте анализа культурологической картины посредством выделения отдельных модулей и модальностей.

\section{Заключение.}

В данной краткой монографической работе группой авторов определены основные маркеры, которые выделяют психологическую культурологию в отдельную науку. Мультипликарный генезис и сильная форма трансграничности заставляют предполагать, что данная наука не может быть включена ни в одну из базовых групп наук - культурологию, психологию или социологию.

Подобно реставрации, которая на современном этапе в силу своей мультипликарности и сильной трансграничности требует сепарирования не только от искусствоведения, но даже и от культурологии, психологическая культурология лишь в своём названии несёт соответствие с психологией и 
культурологией. Как следует из выше описанных свойств новой науки, психологическая культурология пользуется исследовательским и методологическим опытом данных комплексов наук, но в равной степени и социологией, философией, историей, антропологией и ряда других наук.

Таким образом, психологическая культурология на современном этапе развития науки как глобальной системы знаний человека может быть выделена в отдельную науку, которая в дальнейшем может сформировать свой комплекс наук на основе трансграничности и множественности общих маркеров с рядом других смежных и относительно отдалённых комплексов наук.

\section{Список источников информации:}

1. Fuller, Steve. Thomas Kuhn: A Philosophical History for Our Times. Chicago: University of Chicago Press, 2000. - 472 p.

2. Marcuse H. An Essay on Liberation. - Boston, 1969. - 94 p.

3. Авенариус Р. О предмете психологии. - М.: Эдиториа УРСС, 2003. - 211 c.

4. Ананьев Б.Г. Личность, субъект деятельности, индивидуальность. - М.: Директ-Медиа, 2008. - 134 с.

5. Ананьев Б.Г. О проблемах современного человекознания. - СПб.: Питер, 2001. $-272 \mathrm{c}$.

6. Борзова Е.П. Сравнительная культурология. Т. 1. - М.: Литрес, 2013. - 360 c.

7. Введение в историю и философию науки / 2-е изд., испр. и доп. / Под ред. С.А. Лебедева. - М.: Академ. Проект, 2007. - 384 с.

8. Гиппенрейтер Ю.Б. Введение в общую психологию. Курс лекций. - М.: АСТ, 2008 год. - 352 с.

9. Конт О. Дух позитивной философии. (Слово о положительном мышлении) / Перевод с французского И.А. Шапиро. - Ростов н/Д: Феникс, 2003. - 256 с. - (Выдающиеся мыслители). 
10. Конт О. Общий обзор позитивизма / Перевод с французского И.А. Шапиро. Под ред. Э.Л. Радлова. - Изд. 2-е. - М.: Книжный дом «ЛИБРОКОМ», 2011. - 296 с. - (Из наследия мировой философской мысли: история философии).

11. Кун. Т. Структура научных революций. С вводной статьей и дополнениями 1969г. - М.: Прогресс, 1977. - 300 с.

12. Общая психология. В 7-ми т. - М.: Академия, 2007.

13. Поппер К.Р. Объективное знание. Эволюционный подход. Пер. с англ. / К.Р. Поппер. - М.: Эдиториал УРСС, 2002. - 436 с.

14. Поппер К.Р. Предположения и опровержения: Рост научного знания: Пер. с англ. / К.Р. Поппер. - М.: ООО «Издательство АСТ»: ЗАО НПЛ «Ермак», 2004. - 638, [2] c. - (Philosophy).

15. Методы Культурологических Исследований - [сайт]. - Режим доступа: http://worlds-culture.ru/index.php?action=full\&id=456 (дата обращения: 12.06.2016). 